\title{
Midwifery and Midwives Service Scheme: A Panacea for Improvement of Some Maternal and Neonatal Indices in Nigeria-A Brief Review
}

\author{
Prosper Adogu \\ Department of Community Medicine, NAUTH, Nnewi, Nigeria \\ Email: prosuperhealth@yahoo.com
}

Received 24 March 2014; revised 20 April 2014; accepted 28 April 2014

Copyright (C) 2014 by authors and Scientific Research Publishing Inc. This work is licensed under the Creative Commons Attribution International License (CC BY). http://creativecommons.org/licenses/by/4.0/

(c) (i) Open Access

\begin{abstract}
Introduction: Midwifery is the art of caring for women during childbearing. It is practiced throughout the world according to the norms, traditions and cultural practices found in each country. Maternal mortality in Nigeria is high but there are wide variations between the geopolitical zones of the country. Government has established the midwives service scheme (MSS) as part of efforts towards reversing the country's unacceptably high maternal mortality trends. To improve these indices, the MSS in Nigeria engaged newly graduated unemployed and retired midwives to work temporarily in rural areas. The midwives are posted for twelve months to selected primary care facilities linked through a cluster model in which four such facilities with the capacity to provide basic essential obstetric care are clustered around a secondary care facility with the capacity to provide comprehensive emergency obstetric care. This brief review is an attempt at exploring the impact of the midwives service scheme on maternal and neonatal indices in Nigeria. Main content: The outcome of the MSS four years has been an improvement though unevenly and marginally, in these indices in the various geopolitical zones of Nigeria. Improvements have been noticed in maternal indices such as antenatal care attendance, women receiving two doses of tetanus toxoid and number of deliveries by skilled personnel. Also reduction in maternal and neonatal mortality has been observed over the years following introduction of the scheme. Major challenges however, include lack of essential drugs, poor accommodation facilities for MSS staff, irregular payment of their remuneration and lack of water/power supply to some designated facilities for the scheme. Recommendations and conclusions: It is therefore recommended that 24 hours availability of essential drugs at primary healthcare centers be maintained. This should happen in conjunction with regular payment of full entitlements and benefits and provision of secured, habitable and good accommodation for MSS staff. Finally, aggressive community mobiliza-
\end{abstract}


tion should continue in order to engender community involvement and participation for sustainable program development.

\author{
Keywords
}

Midwifery, Midwives Service Scheme, Maternal and Neonatal Indices, Nigeria

\title{
1. Introduction
}

Midwifery is practiced throughout the world according to the norms, traditions and cultural practices entrenched in each country, in the same way that midwifery standards and their training curriculum vary from country to country [1]. Even though the International Confederation of Midwives (ICM) regulates midwife training and practice, yet informally trained midwives are often not covered by such regulations [1]. Early in the 21st century, the scope of midwifery did not just include the care of obstetric needs of women but also taking care of their gynecological needs throughout their life. Globally, two approaches to licensed midwifery practice are consistently found: nurse-midwives and direct-entry midwives. The latter, which is the more common approach, enters health care practice directly as midwives rather than through any other health profession, while the former involves post-nursing education. Countries such as Canada, Ghana, Kenya, the United Kingdom, and the United States train both types of midwives. However other countries like Cameroon, Uzbekistan, Nigeria and Sierra Leone license only nurse-midwives, whereas Côte d'Ivoire, Vietnam, and Ethiopia encourage only direct-entry midwifery. Direct-entry midwives in the United States are designated certified midwife (CM) or certified professional midwife (CPM), if certified by the American Midwifery Certification Board or the North American Registry of Midwives, respectively. Conversely, nurse-midwives are trained as nurses first and then move on to acquire midwifery training as a postgraduate component either at the certificate or master's level. Irrespective of the type of midwife, they all attend to births either in women's homes, or maternity/hospital settings [1] and they have a big role to play in the maternal mortality ratio reduction in developing countries such as Nigeria.

There is a general belief that maternal mortality ratio in Nigeria remains at an embarrassing high level and is deemed to be one of the highest in the developing world [2]. A woman's chance of dying due to complications around pregnancy and birth in Nigeria is $1 / 15$, compared to $1 / 5000$ in developed nations. It is estimated that more than 53,000 women and 250,000 newborns die each year due to preventable causes [3]. Furthermore, the average maternal mortality ratio in northern Nigeria has been 2400 (range: 1060 - 4477) per 100,000 live births [4]-[7], while similar data in the southern parts of the country were considerably lower; and within the range of 450 and 750/100,000 live births [8] [9]. Maternal mortality has continued to be one of the most serious challenges in Nigeria, and until recently; despite several efforts (policies, initiatives and instruments etc.) the country has achieved only marginal progress with this most basic indicator of health and development.

The direct consequence of this reality (poor maternal and neonatal indices) was the establishment of Midwives Service Scheme (MSS) which focus was to ensure the availability of skilled birth attendants to reduce maternal, infant and child mortality. The Midwives Service Scheme is a Millennium Development Goal (MDG) supported project being jointly carried out by the Nigeria Governments at federal, state and local government levels. Under the scheme, midwives are deployed to health facilities in rural communities to enhance skilled attendance at birth and hopefully aid reduction in maternal, newborn and child mortality and morbidity. The scheme seeks to mobilise midwives, especially newly qualified midwives, to health facilities in rural communities to undertake a one year community service. The MSS is therefore set to address the human resource need for skilled attendance at the primary level of care as the majority of Nigeria's obstetric population reside in the rural area [10]. This review briefly explores the contributions of the MSS towards improving maternal and neonatal indices in Nigeria.

\section{Main Content}

The midwives service scheme has five key components including [3]: 1) community participation which recognizes the role of the community in the success of the scheme, and involves local ward development committees (WDC) across all 652 primary health care (PHC) facilities, 2) deploying skilled birth attendants in rural com- 
munities. More than 2,600 trained midwives have been deployed at PHC facilities to support more mothers and babies across Nigeria, 3) PHC support with basic equipment and supplies for midwives who need them. These include blood pressure apparatus, stethoscopes, scales, midwifery kits, essential drugs and consumables as well as service guidelines, 4) capacity building and training of midwives to improve the quality of care. This is given in addition to their traditional midwife training. For instance, when all midwives are trained in life saving skills (LSS) and integrated management of childhood illness (IMCI), this ensures they acquire the necessary skills needed to save lives and 5) Information technology communications support which is aimed at connecting midwives to other health workers and support services through a new communication system. In addition to voice and data transmission, midwives can use internet and video conferencing that can work with mobile technology.

The MSS is delivered using a "cluster" or "spoke and hub" model [3]: Four PHC facilities which have the capacity to perform basic obstetric care are clustered around a general hospital to which the PHC facilities can send patients for emergency care. The scheme currently has 163 clusters comprising 652 PHCs clustered around 16 general hospitals. To ensure the scheme's success, a memorandum of understanding has been signed between the Federal and State Governments. It has the support of strategic partners including WHO, UNICEF, UNFPA, PRRINN-MNCH, Pathfinder International, ACCESS/JEPHIGO and PPFN. The scheme is also part of Nigeria’s commitment to the United Nations Millennium Development Goal (MDG) 5, which sets out to improve maternal health and reduce maternal mortality rate by three quarters by the year 2015 .

To ensure the programme achieves its objective of reducing maternal, infant and child mortality, the MSS has outlined a set of targets to be achieved by 2015. These include [3]: 1) to ensure all midwives recruited under MSS are trained in LSS and IMCI, 2) To increase the proportion of primary health care facilities offering a twenty-four hour, qualified midwife-managed service by $80 \%, 3$ ) to increase the proportion of pregnant women receiving antenatal care from $60 \%$ to $80 \%, 4$ ) to increase the proportion of primary health care facilities providing basic essential/emergency obstetric care (BEOC) by 60\%, 5) to increase the proportion of deliveries attended to by skilled birth attendants from $36.3 \%$ to $72.6 \%, 6$ ) to increase contraception (Family Planning) uptake from $13 \%$ to $50 \%$ and 7 ) to reduce maternal, newborn and child mortality by $60 \%$.

While there is still much work to be done to meet both the targets of MDG 5 and 2015 programme goals, there has been some remarkable progress recorded to date. Such concrete results achieved so far include: 1) More than 2600 midwives have been deployed to over 650 rural health centers across Nigeria, 2) About 650,000 Mama kits for safe delivery have been distributed, 3) About 2300 midwives have been trained in life-saving skills, 4) Six hundred and fifty rural centers now have communication links to the national operations hub, and 5) About 160 medical officers are now trained in emergency obstetrics. The MSS programme is driven by the National Primary Health Care Development Agency (NPHCDA) goal of improving access to basic healthcare services, and the United Nations Millennium Development Goal 5 of improving maternal health.

There is some noticeable evidence of improved maternal health over the years following introduction of the MSS, and which has been depicted in the figures below. Figure 1 compares facility based maternal indicators' percentage increase in 2009/2010 with that recorded in 2013. The percentage increases in incidence of deliveries and women receiving two doses of tetanus toxoid were markedly higher in 2013 compared to 2009/2010, while the percentage increase for total ANC visits was only marginally higher in 2013 than in 2009/2010. In the same vein, Figure 2 depicts a downward trend and progressive reduction in the MMR from 2009 to 2013. Similarly, Figure 3 shows a marked fall in neonatal mortality ratio from 2009 to 2010 but has remained almost the same since then till 2013.

Despite the apparent successes recorded by the scheme, the MSS is not without some challenges: If the programme is to effectively and sustainably meet its objective of facilitating reduction in maternal and child mortality, problems of lack of essential drugs, poor/secure accommodation facilities for MSS staff, non regular payment of their remuneration and lack of water/power supply to some designated facilities for the scheme, should be addressed. A good example of the problems and challenges still faced by the scheme is seen in the result of a pilot survey carried out in 10 selected health facilities in Sokoto state, Nigeria that runs the midwives service scheme [11]. The survey was focused on essential variables required to operate such centres under the scheme. The variables included drugs and consumable availability, working environment, MSS Staff remuneration/salaries, human resources situation at the facilities, health services provided and referral system in MSS facilities. From the results of the survey, it was noted that as at the time of visit, most of the essential drugs such as misoprostol, magnesium sulphate and oxytocin, haematinics were available in only two to three out of the 10 health facilities in which the MSS pilot survey was conducted. On accommodation, five out of the 10 facilities have accommodation within 1kilometer. This it was noted perhaps accounted for why 24 hours coverage was provided 


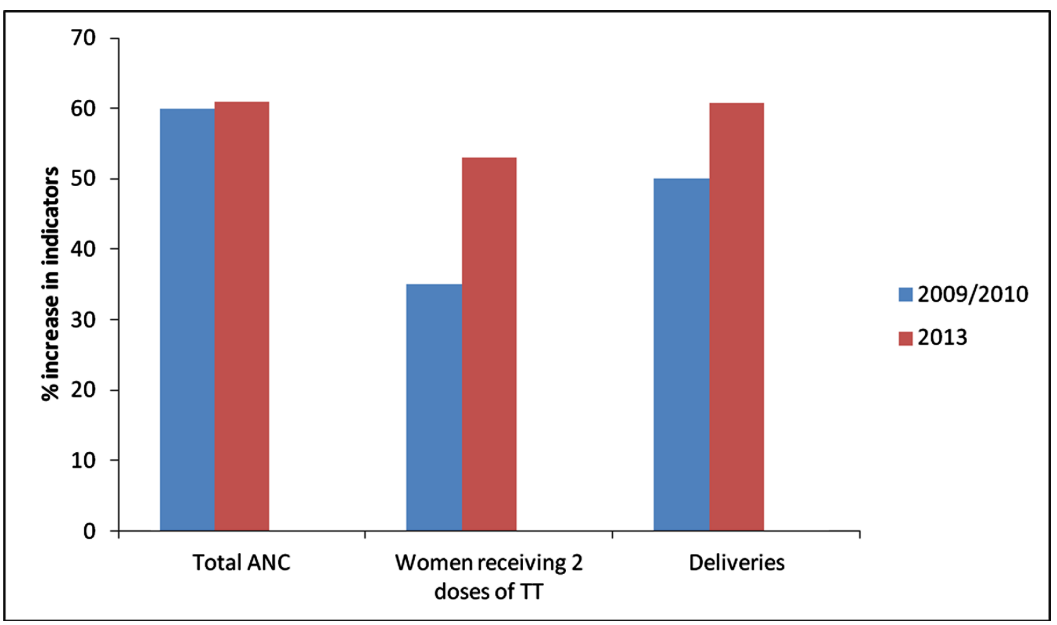

Figure 1. MSS facility based maternal indicators percentage increase 2009/2010 versus 2013 [12] [13]. Key: ANC—Antenatal care, TT = tetanus toxoid.

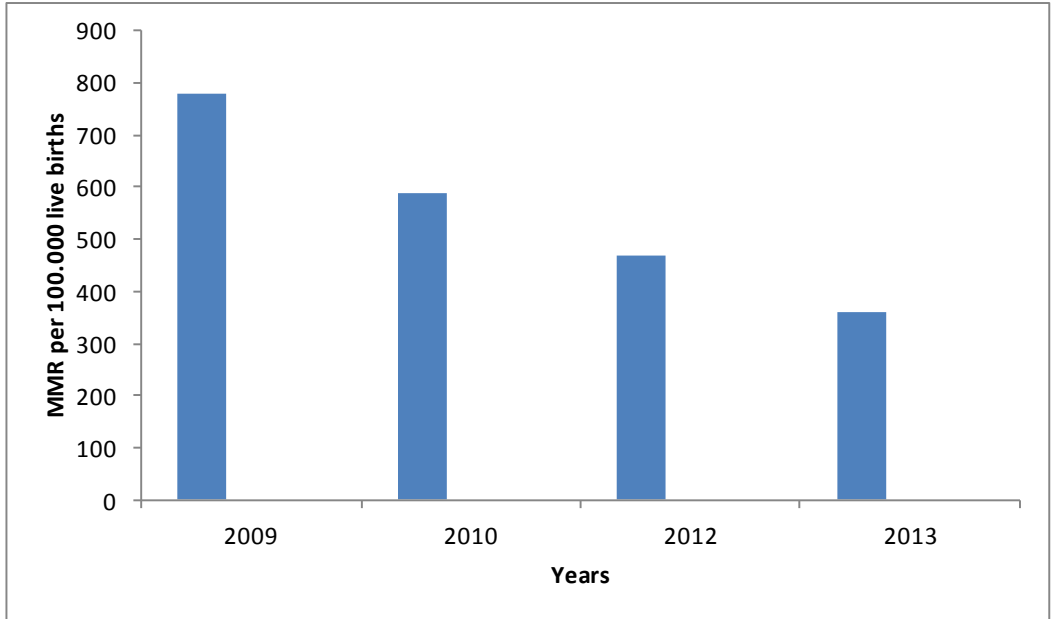

Figure 2. Trend in MSS facility based maternal mortality ratio from 2009 to 2013 [12] [14]. NB: Data for 2011 were unavailable.

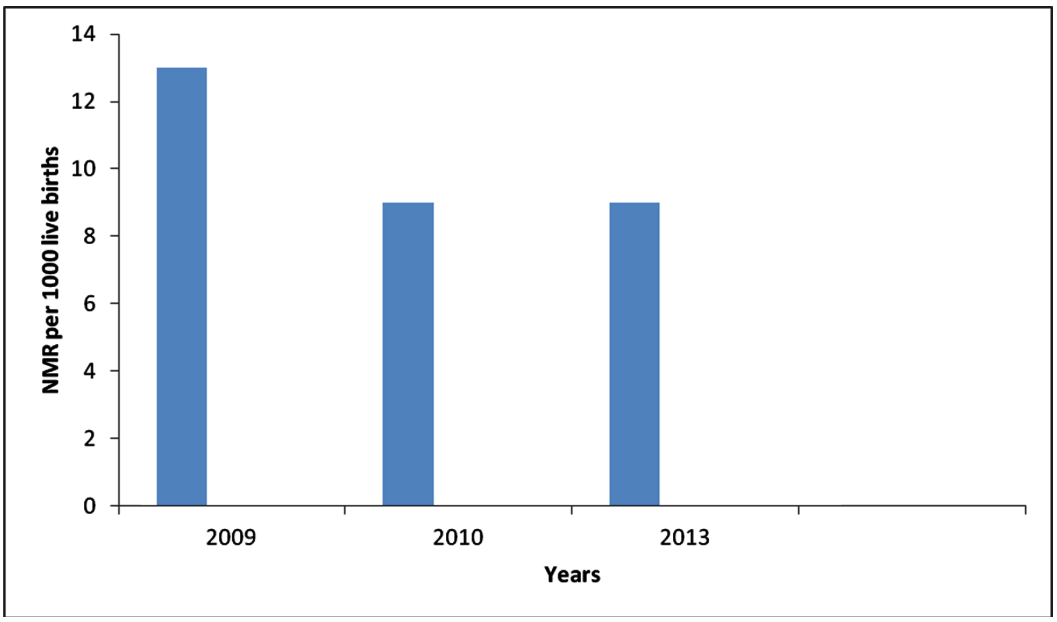

Figure 3. Trend in MSS based neonatal mortality rate from 2009 to 2013 [12] [13]. NB: Data for 2011 and 2012 were unavailable. 
in only five facilities. The MSS workers in all facilities providing maternal care were supposed to be housed to be able to carry the 24 hours coverage. If the midwives are not accommodated within the facility or nearby, it will be very difficult for them to attend to patients especially when it is known that most deliveries occur at night. Also, only six facilities were reported to have functional water source within the health facility as at the time of the visit. On the human resource situation, none of the facilities had medical doctors while only two facilities have laboratory technicians. On the MSS staff remuneration/salaries, the outcome of the survey indicated that MSS staff in five of the facilities reported getting their salaries by federal government of Nigeria (FGN) monthly while those with non regular payment by FGN were also in five other facilities.

MSS workers in nine out of the 10 facilities surveyed, receive their state payment monthly.

Local government area payment is reported to be regular in seven facilities. However all facilities provide ante natal care, delivery service, health talk and family planning services.

Only two facilities do not provide outreach services while one facility does not provide under- 5 and tetanus toxoid vaccination services. Challenges of MSS Staff as noted by the outcome of the survey were non regular payment especially by federal government, poor/lack of secured accommodation facilities, lack of water and power supply to some facilities and lack of essential drugs in the facilities.

\section{Recommendations and Conclusions}

In the light of the foregoing issues and challenges raised, the following recommendations are hereby proffered to guarantee even greater successes by the program:

1): Ensuring 24 hours availability of essential drugs at primary healthcare centers.

2): Regular payment of full entitlements and benefits by NPHCDA, states and local governments in line with the signed and agreed memorandum of understanding (MOU).

3): Provision of secured, habitable and good accommodation either within reach or at least one kilometre radius of the facility as well as functional water system within the health facility.

4): There should be proper budget tracking, analysis and accountability with a view to improving on facility services and collaborating in the area of MSS strategy to reduce maternal and child mortality. It is necessary to track how the programme is faring at the grassroots so that the reason for which the intervention was launched in 2009 is not defeated.

5): The involvement and participation of community as key stake-holders is essential to the initiation and sustenance of an effective partnership needed for the attainment of the specific objectives of the policy. For example, in Thailand, some of these challenges were circumvented through the deployments of readily available community human resources (indigenous mid-wives), general development of rural areas and career development incentives for these midwives [15] [16]. This is strongly recommended for the Nigerian situation.

While MSS is a step in the right direction, what is needed to achieve the desired program goals is to ensure adequate coverage especially in the northern parts of the country, as much as the ongoing violence (Boko Haram Insurgence) in the area would allow. Governments should demonstrate adequate political will and commitment by providing an enabling environment with proper supervision and appropriate motivation of MSS staff and community for full participation and eventual program ownership.

\section{References}

[1] Connerton, W.C. (2012) Center for Health Outcomes and Policy Research. University of Pennsylvania School of Nursing. Contributions on "Midwifery" in Encyclopaedia Britannica (last updated 25 May 2012). http://www.britannica.com/EBchecked/topic/381708/midwifery/302928/Midwifery-in-the-modern-e

[2] Harrison, K.H. (2009) The Struggle to Reduce High Maternal Mortality in Nigeria. African Journal of Reproductive Health, 13, 9-20.

[3] National Primary Healthcare Development Agency (NPHCDA) (2013) Making Nigerians Healthy. Report on Midwives Service Scheme.

[4] Ujah, I.A., Aisien, O.A., Mutihir, J.T., Vanderjagt, D.J., Glew, R.H. and Uguru, V.E. (2005) Factors Contributing to Maternal Mortality in North-Central Nigeria: A Seventeen Year Review. African Journal of Reproductive Health, 9, 27-40. http://dx.doi.org/10.2307/3583409

[5] Ochejele, S., Enegela, J. and Heywood, A. (2004) Assessment of Quality of Emergency Obstetrics Care at the Federal Medical Centre, Makurdi, Nigeria. Tropical Journal of Obstetrics and Gynaecology, 21, 160-163. 
[6] Yusuf, M.A., Hamisu, M.S., Nalini, S.K. and Greg, R.A. (2003) Maternal Mortality in Northern Nigeria: A Population Based Study. European Journal of Obstetrics \& Gynecology and Reproductive Biology, 109, 153-157. http://dx.doi.org/10.1016/S0301-2115(03)00009-5

[7] Yusuf, M.A. (2005) Pattern of Maternal Morbidity and Mortality in Kano State: A Geographical Analysis. Journal of Management \& Social Sciences, 9, 196-221.

[8] Onakewhor, J.U. and Gharoro, E.P. (2008) Changing Trends in Maternal Mortality in a Developing Country. Nigerian Journal of Clinical Practice, 11, 111-120.

[9] Onah, H.E., Okaro, J.M., Umeh, U. and Chigbu, C.O. (2005) Maternal Mortality in Health Institutions with Emergency Obstetric Care Facilities in Enugu State, Nigeria. Journal of Obstetrics \& Gynaecology, 25, 569-574. http://dx.doi.org/10.1080/01443610500231484

[10] Population Reference Bureau (2001) World Population Data Sheet. Washington DC: Population Reference Bureau 2001. http://www.prb.org/Content/Navi-gationMenu/Other reports/2000-2002/sheet4.html

[11] Rakiya A Mohamed (2013) Nigeria: Challenges of the Midwives Scheme. 1-2. http://allafrica.com/search/

[12] Abimbola, S., Okoli, U., Olubajo, O., Abdullahi, M.J. and Pate, M.A. (2012) The Midwives Service Scheme in Nigeria. PLoS Medicine, 9, e1001211. http://dx.doi.org/10.1371/journal.pmed.1001211

[13] Nigerian Demographic and Health Survey (2013) Preliminary Report, Nigeria Demographic and Health Survey. National Population Commission, MEASURE, DHS, ICF International, Calverton, Maryland, 20-24.

[14] Commonwealth Health Online; Facts and Figures: 2012 and 2013. www.commonwealthhealth.org.

[15] MoH Malawi Human Resources in the Health Sector: Towards a Solution (2004) Lilongwe: Ministry of Health.

[16] Wibulpolprasert, S. and Pengpaibon, P. (2002) Integrated Strategies to Tackle the Inequitable Distribution of Doctors in Thailand: Four Decades of Experience. Human Resources for Health, 1, 12.

http://www.humanresourceshealth.com/content/1/1/12.

\section{List of Abbreviations}

NAUTH-Nnamdi Azikiwe University Teaching Hospital

MSS-Midwives Service Scheme

ICM-International Confederation of Midwives

CF_Certified Midwife

CPM-Certified Professional Midwife

MDG-Millennium Development Goals

WDC_-Ward Development Committee

PHC_-Primary Health Care

LSS_Life Saving Skill

IMCI-Integrated Management of Childhood Illness

WHO-World Health Organization

UNICEF-United Nation Children's Fund

UNFPA — United Nations Population Fund

PRRINN-MCH_-Partnership for Reviving Routine Immunization in Northern Nigeria, Maternal, Newborn and Child Health Initiative.

PPFN_Planned Parenthood Population of Nigeria

BEOC-Basic Essential Obstetric Care

NPHCDA-National Primary Health Care Development Agency

ANC-Antenatal Care

TT-Tetanus Toxoid

FGN-Federal Government of Nigeria

MOU-Memorandum of Understanding

MMR-Maternal Mortality Ratio 